Journal of Educational

and Psychological Sciences

Volume (4), Issue (44): 30 Nov 2020

P: $101-113$
AJSRP

ISSN: 2522-3399

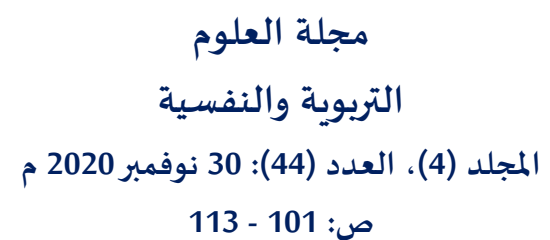

ص: 101 - 113

\title{
The reality of e-learning in the distance learning program in light of the emerging Corona pandemic "Covid-19" from the viewpoint of students in Jordan between theory and practice
}

\author{
Faisal Saleh Freah Aljarrah \\ Ministry of Education || Jordan
}

\begin{abstract}
The aim of this research is to identify the reality of e-learning in the distance learning program in light of the emerging Corona pandemic "Covid 19" from the viewpoint of students in Jordan between theory and practice. To achieve the goal of the study, the researcher prepared an electronic questionnaire that included (20) items distributed to the research sample electronically. It was confirmed its sincerity and consistency, and it was applied to a random sample from the study community consisting of (1200) students, and the descriptive analytical method was used. An analytical descriptive approach was used, The study concluded the following results: The importance of using e-learning in distance learning programs, the extent of using e-learning in distance learning programs. There are difficulties preventing the use of e-learning in distance learning programs. There were no statistically significant differences at $(05.0 \leq \alpha)$ between the responses of the sample members of students about the reality of e-learning in distance learning programs due to gender variables.

In light of these results, the study recommended encouraging and educating students to take advantage of the e-learning technology in order to facilitate and improve educational learning practice under the current circumstances. And strengthening the positive trend towards employing e-learning technology and benefiting from Arab and international experiences and expertise in the field of employing e-learning technology in distance learning programs.
\end{abstract}

Keywords: e-learning, distance learning, students.

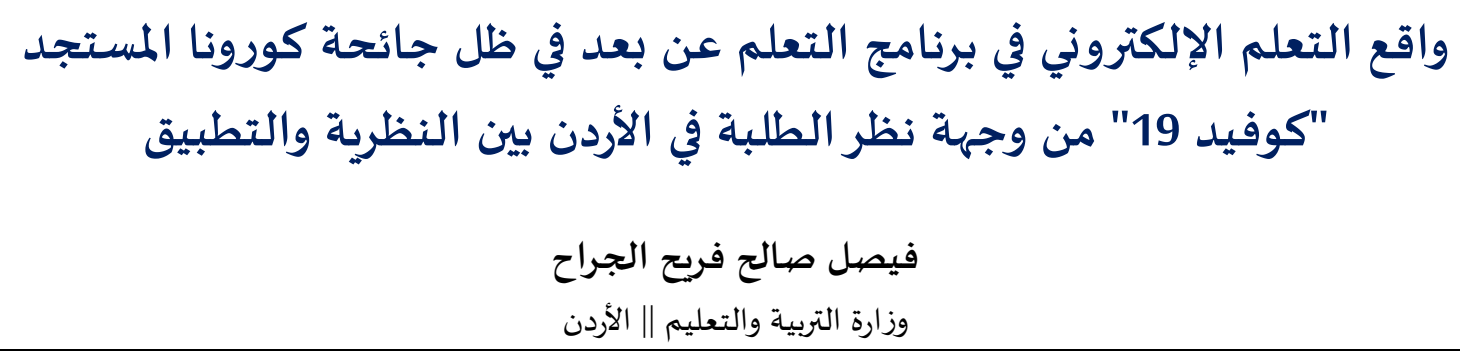

الملخص: هدف هذا البحث إلى التعرف على واقع التعلم الإلكتروني في برنامج التعلم عن بعد في ظل جائحة كورونا المستجد "كوفيد 19"

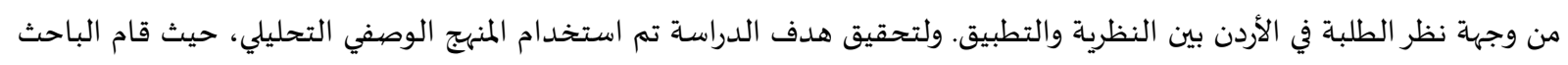

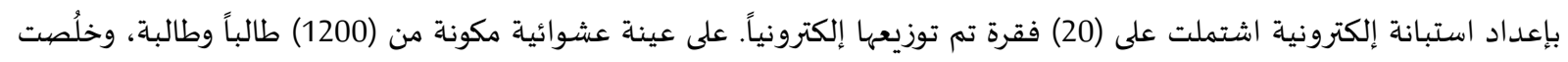

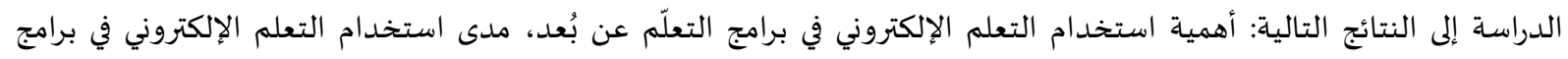

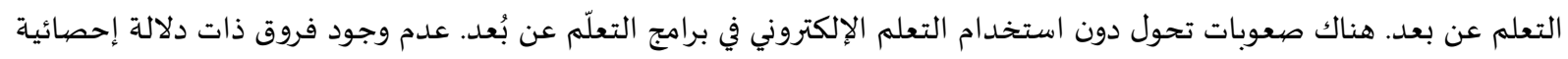

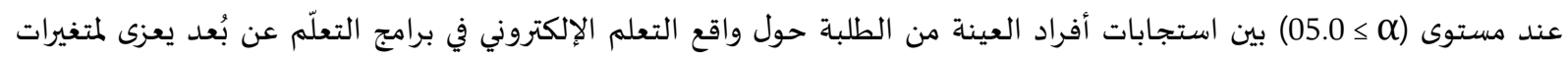

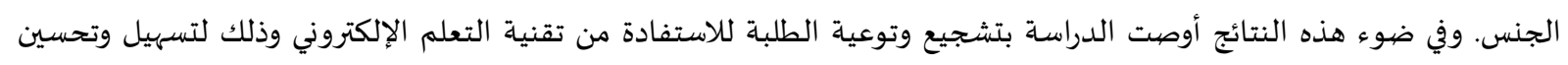


الممارسة التعليمية التعلمية في ظل الظروف الحالية. وتقوية الاتجاه الإيجابي نحو توظيف تقنية التعلم الإلكتروني والاستفادة من تجارب والخبرات العربية والعالمية في مجال توظيف تقنية التعلم الإلكتروني في برامج التعلّم عن بعُد.

تعتبر تجربة استخدام التعلم الإلكتروني في برنامج التعليم عن بعد، مبادرة ابتكارية ذات أثر استراتيجي

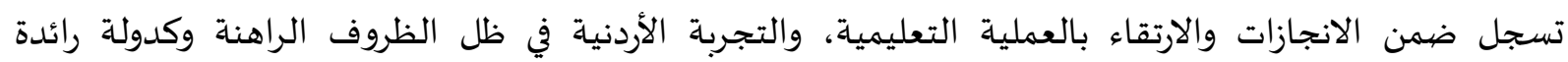

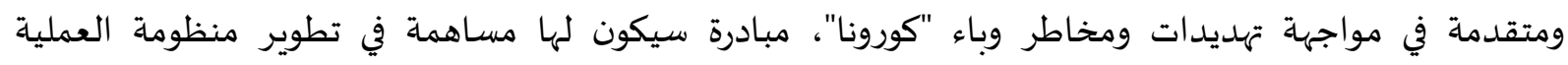

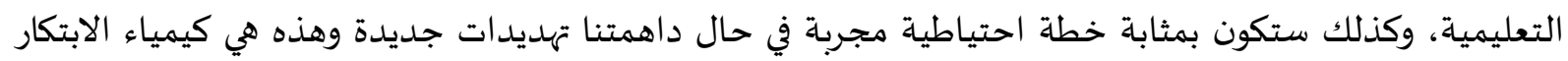

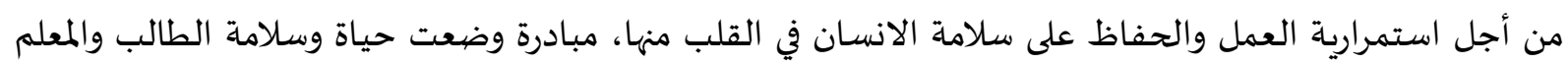

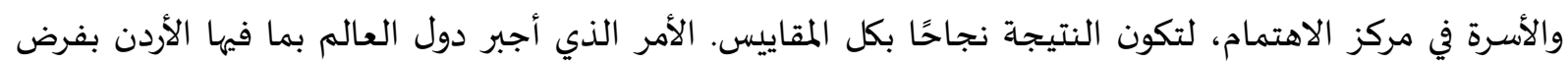

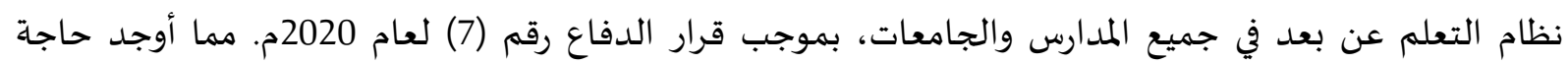

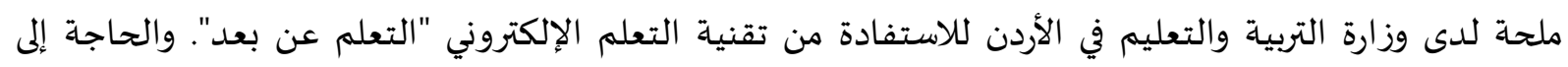

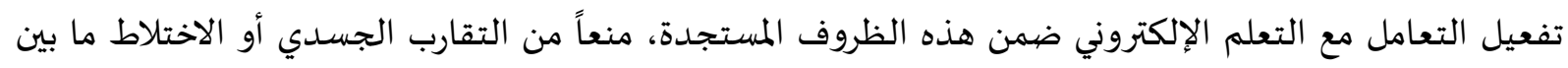

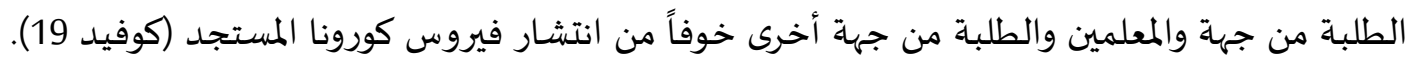

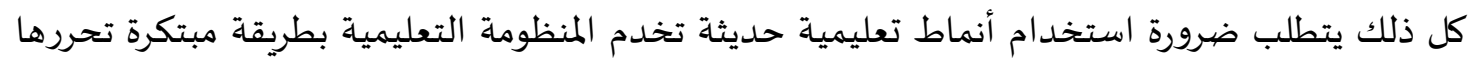

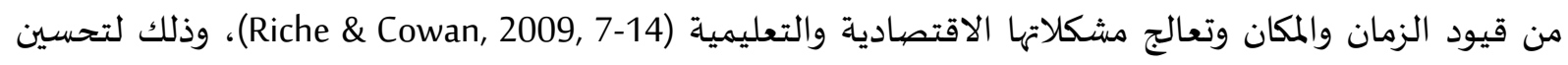

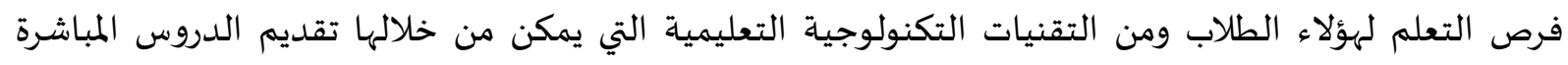

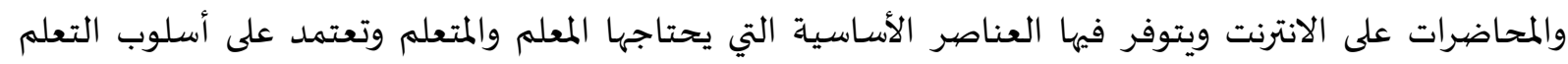
التفاعلي " تقنية الفصول الافتراضية" (Florence \& Michele, 2014, 193)، فهي بيئة تعلم وتعليم تفاعلية تحتوي الإنيا على مجموعة من الأنشطة التي تحاكي أنشطة الفصل الفيزيقي المعتاد يقوم بها معلم وطلاب يفصل بينهم حواجز

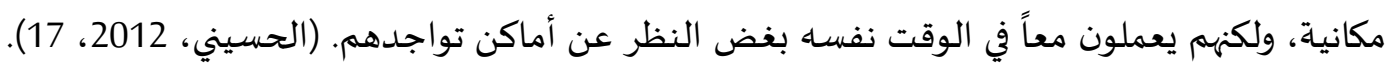

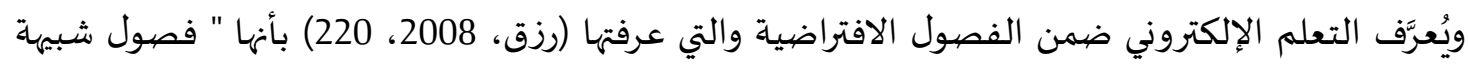

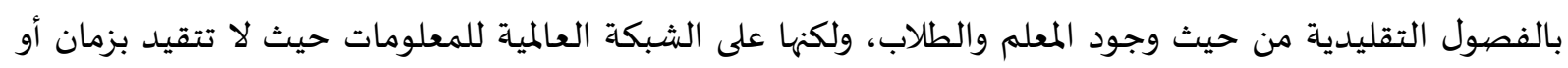

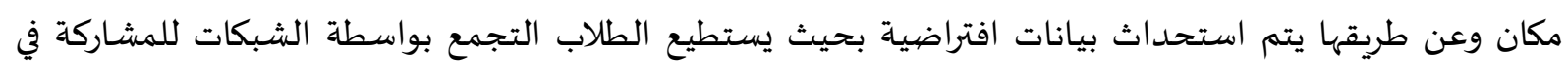

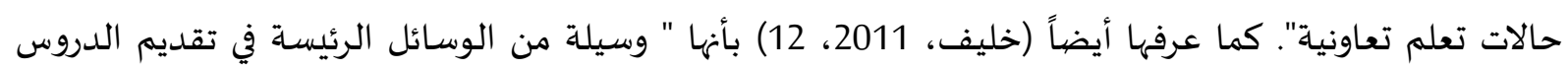

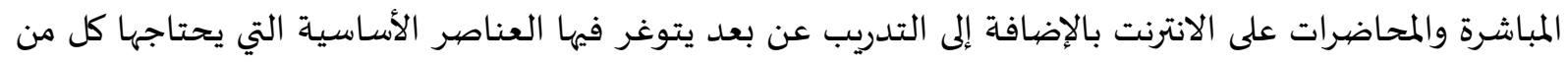

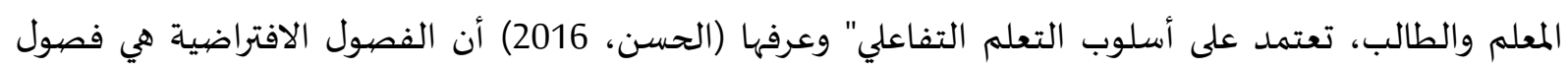

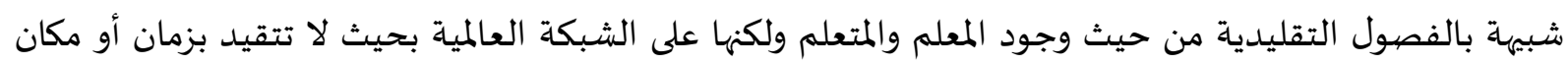
وعن طريقها يتم استحداث بيئات تعليمية افتراضية.

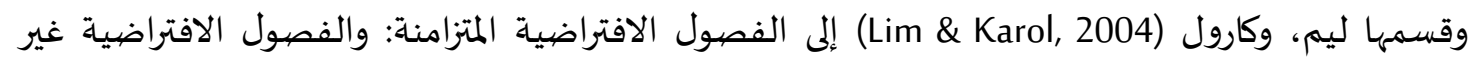

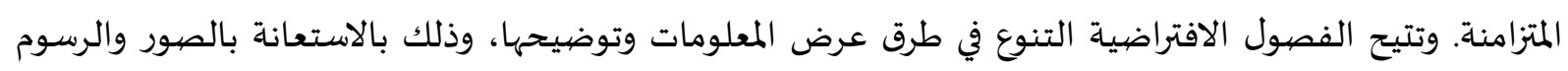

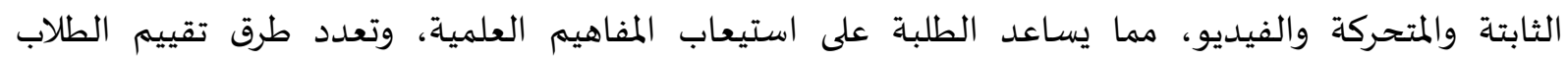
ومتابعتهم، وتتيح لهم التعرف على مستوى تحصيلههم الدراسي ويسهل على المعلم توجيههم وارشادهم، وتنمية القدرات 
العقلية لدى الطلبة، وذلك من خلال تبادل الآراء والأفكار ووجهات النظر، كما تتيح تبادل إرسال ملفات والواجبات

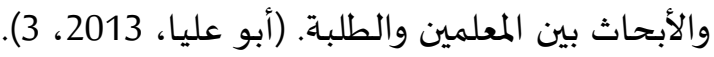

كما أن التعلم الإلكتروني يحث الطلبة على طلب المساعدة الإلكتروني بمفردة بعيداً عن زملائه في البيئة التعليمية مقارنة بالفصل التقليدي يجبره على طلب المساعدة التعليمية من الأخرين، والاستفادة من الامكانات

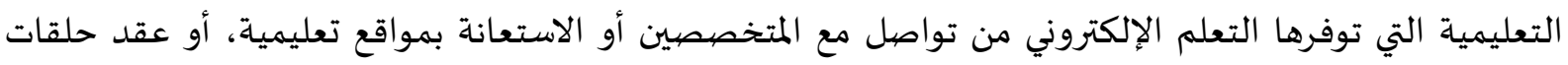

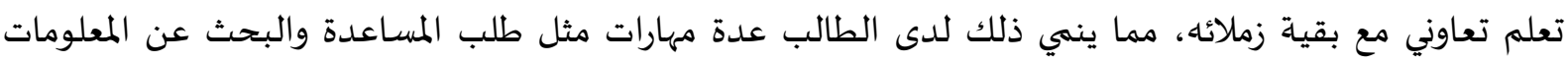
وتعلم الأقران. (Wang, Newlin, 2002).

وقد جاء هذا البحث للتعرف على واقع تطبيق نظام التعلم الإلكتروني في برنامج التعلم عن بعد وباستخدام

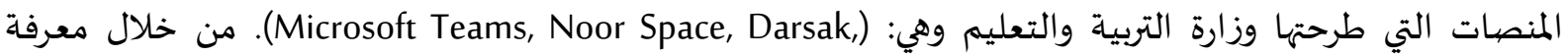
الأسس والمتطلبات اللازمة لتحقيقها، والكشف على معوقات التطبيق. وكنموذج كانت مدارس مديرية التربية والتعليم

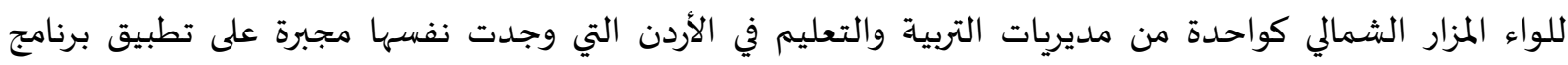

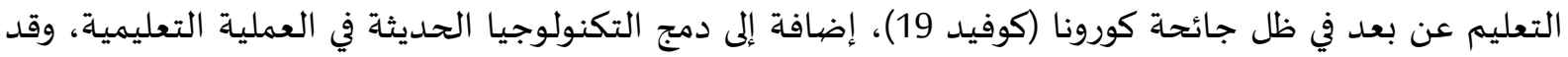

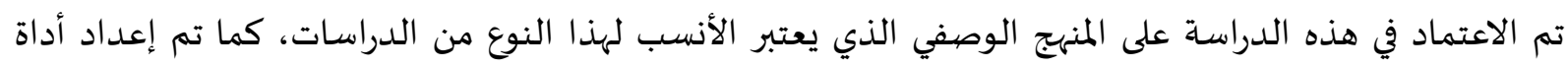
جمع البيانات والتي تمثلت في استبادة.

مشكلة البحث:

لقد نبع الشعور بمشكلة البحث من خلال ما يلي: ظهور جائحة كورونا المستجد (كوفيد 19) الأمر الذي

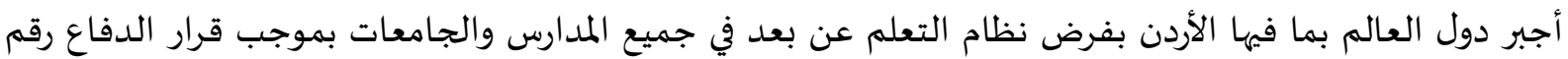
(7) لعام 2020م، مما أوجد حاجة ملحة لدى دول العالم للاستفادة من تقنية التعلم الإلكتروني "التعلم عن بعدئ.

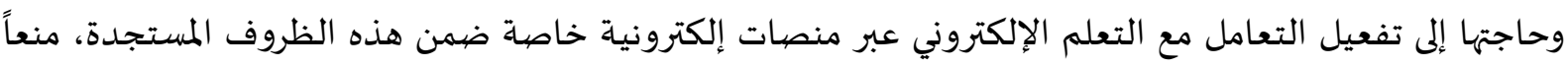

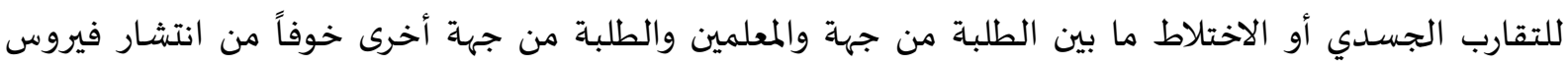
كورونا المستجد (كوفيد 19).

أسئلة البحث:

$$
\text { تتحدد مشكلة البحث في السؤال الرئيس الآتي: }
$$

ما واقع التعلم الإلكتروني في برنامج التعلم عن بعد في ظل جائحة كورونا المستجد "كوفيد 19" في الأردن بين النظرية والتطبيق؟

$$
\text { ومن سؤال الدراسـة الرئيس انبثق السؤال الفرعي التالي: }
$$

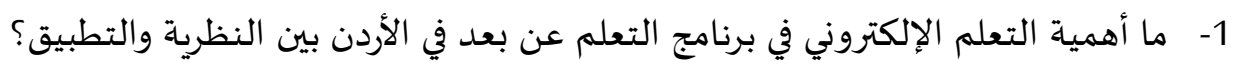

$$
\text { فرضيات البحث: }
$$

$$
\text { وتتمثل فرضية الدراسة فيما يلي: }
$$

1. لا توجد فروق ذات دلالة إحصائية عند مستوى الدلالة ( (م 05.0 بين استجابات عينة الدراسة نحو

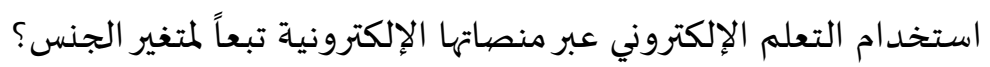




$$
\text { أهداف البحث: }
$$

يهدف البحث الحالي إلى الآتي:

1- تسليط الضوء على أهمية التعلم الإلكتروني عبر منصاتها الإلكترونية التالية ) Noor Space, Microsoft

Teams, Darsak

2- التعرف على آراء الطلبة نحو استخدام التعلم الإلكتروني عبر منصاتها الإلكترونية.

3- الوقوف على الصعوبات التي تحد من استخدام التعلم الإلكتروني من وجه نظر الطبر الطلبة.

أهمية البحث:

ترجع أهمية هذا البحث إلى:

جاءت أهمية هذا البحث متزامنة؛ مع اهتمام الأردن بظهور جائحة كورونا المستجد (كوفيد 19) الأمر الذي

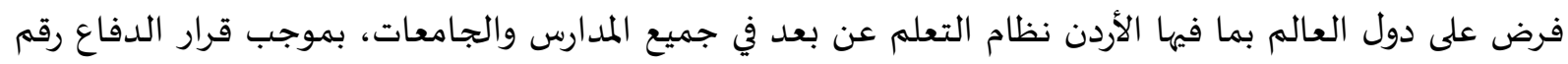
(7) لعام 2020م. مما أوجد حاجة ملحة لدى دول دول العالم للاستفادة من تقنية التعلم الإلكتروني.

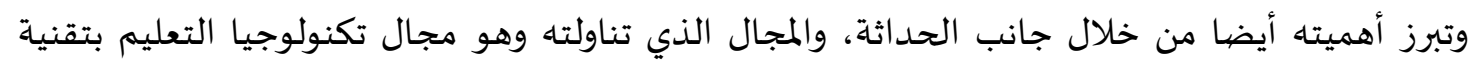
(التعلم الإلكتروني) عبر المنصات الإلكترونية التي طرحتها وزارة التربية والتعليم التالية: ( Noor Space, Microsoft

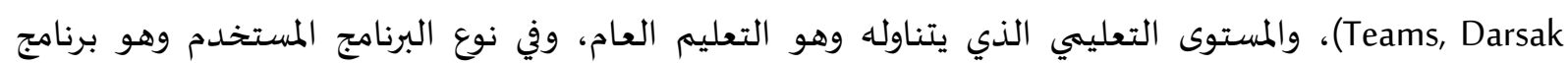

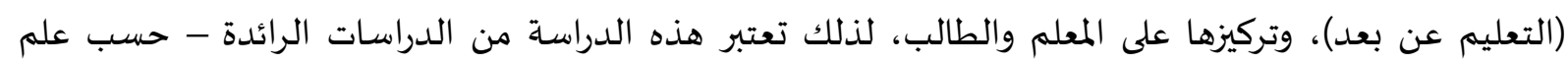
الباحث- في هذا المجال في الأردن.

حدود البحث:

اقتصر البحث الحالي على الحدود الآتية:

الحدود الموضوعية: تقدير واقع التعلم الإلكتروني في برنامج التعلم عن بعد في ظل جائحة كورونا المستجد المدائ "كوفيد 19" في الأردن بين النظرية والتطبيق. الحد البشري: طلبة مديرية التربية والتعليم للواء المزار الشمالي لئلئ في الأردن. الحد المكاني: مديرية التربية والتعليم للواء المزار الشمالي- الأردن.

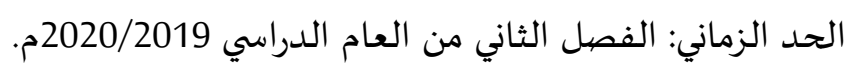

المصطلحات (التعريفات الإجرائية):

- التعلم الإلكتروني: ويعرفها الباحث إجرائياً " هي بيئة تعليم وتعلم تفاعلية تسمح بالتفاعل المعات الحي بين المعلم

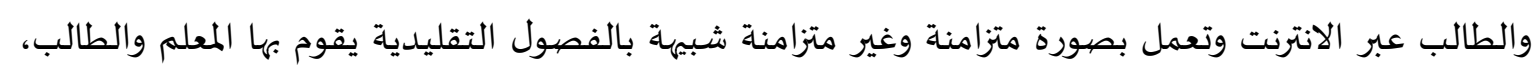

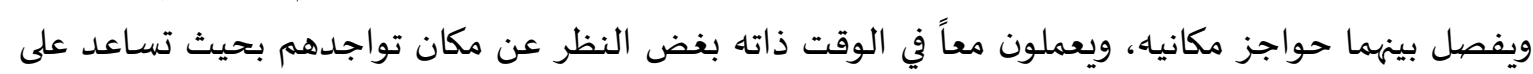
تنمية التحصيل المعرفي لديهم". - ـ ـ التعليم عن بعد: ويُعرفه الباحث إجرائيا بأنه" نمط تعليمي تعلمي غير تقليدي يتبع مديرية التربية والتعليم

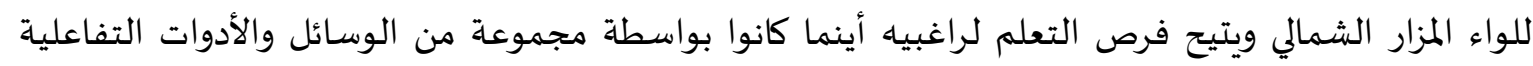

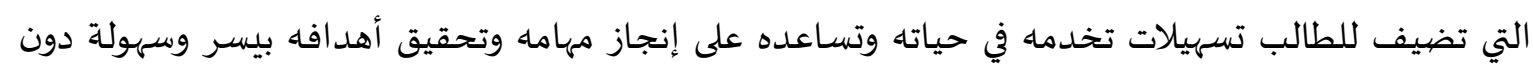


الطلبة: عرفه الباحث إجرائياً على أههم" جميع الطلبة في مدارس مديرية التربية والتعليم للواء المزار الشمالي

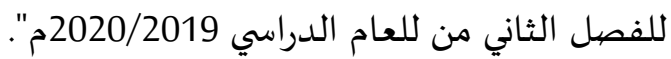

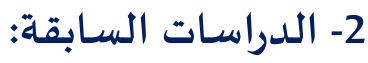

وهناك بعض الدراسات التي تناولت أهمية التعلم الإلكتروني ومن أهمها:

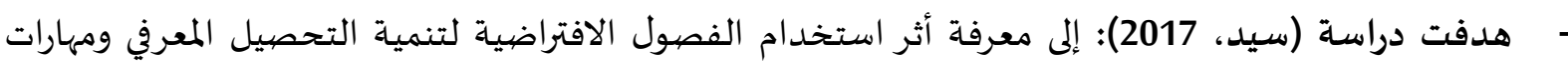

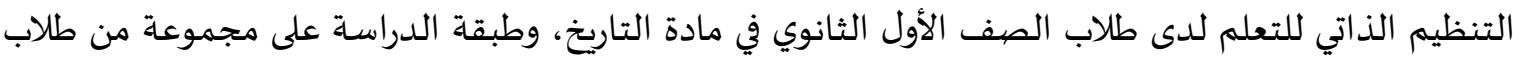

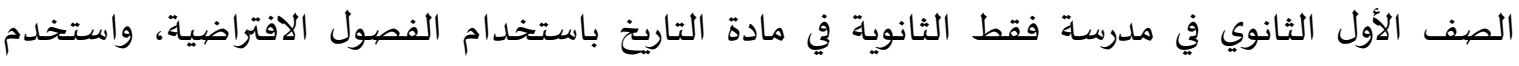

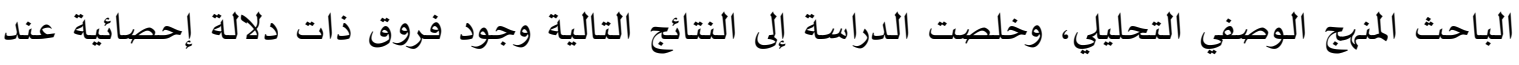

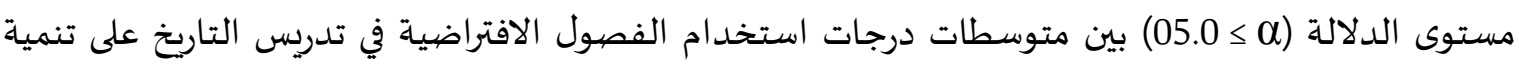

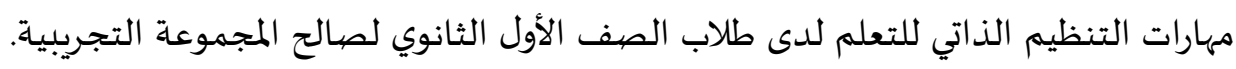

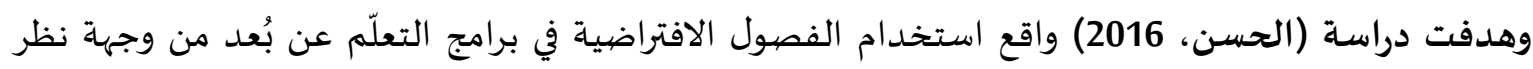

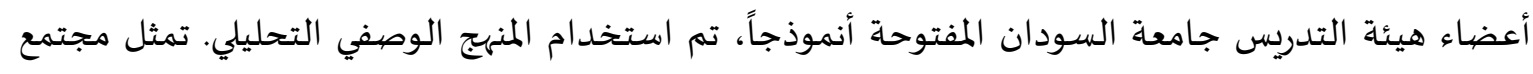

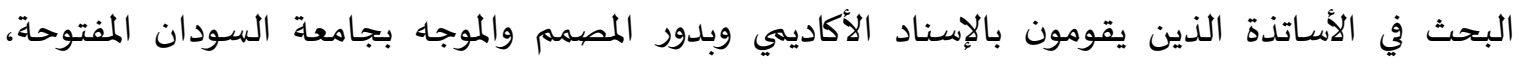

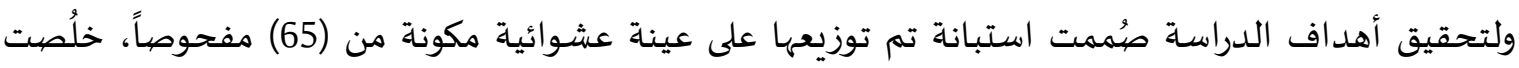

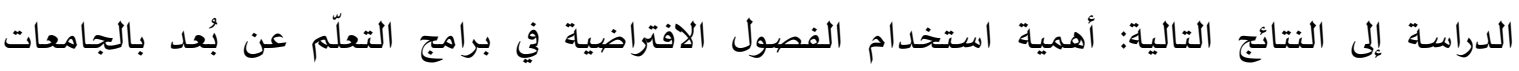

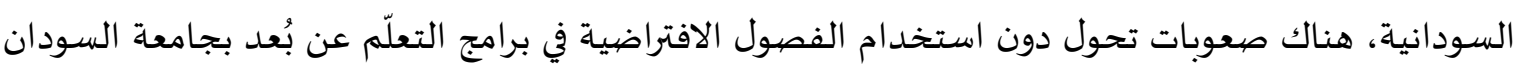
المفتوحة. وهدفت دراسة (بدير، 2014)، إلى الكشف عن فاعلية استخدام تكنولوجيا الواقع الافتراضي القائم على التعليم الذاتي في تدريس العلوم على التحصيل المعرفي وتنمية التفكير البصري والاتجاه نحو مادة العلوم لديهيه.

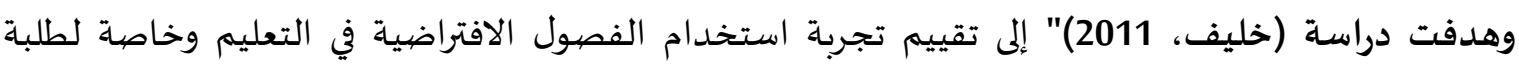

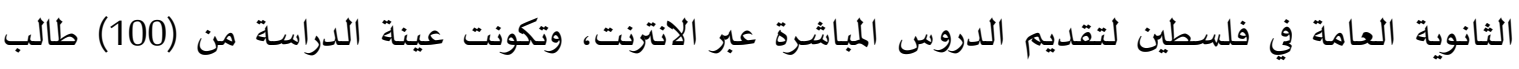

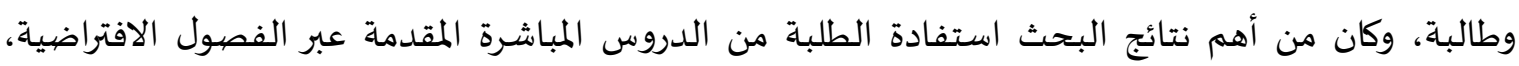

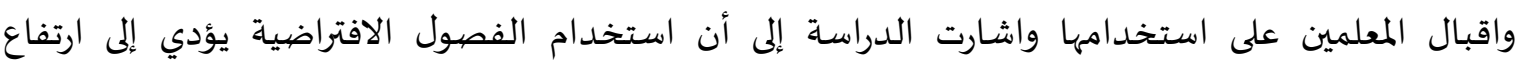

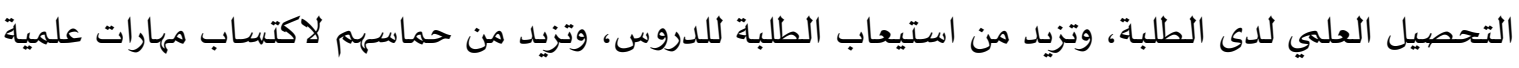

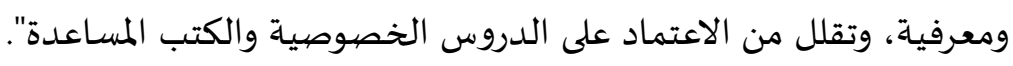

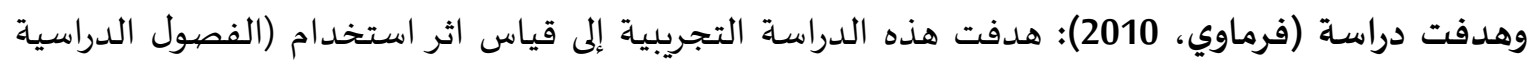

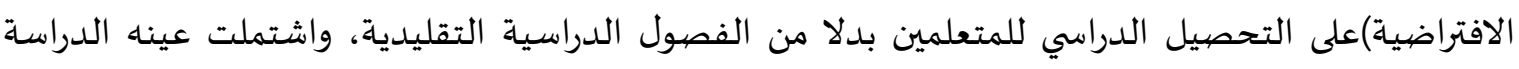

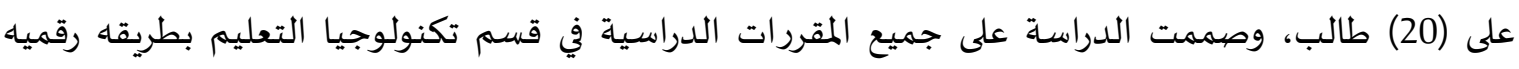

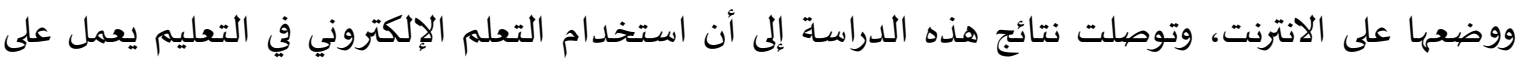

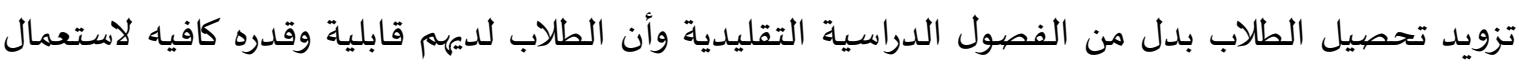
التكنولوجيا والتفاعل معها وإحساسهم بالثقة والمسؤولية تجاهيا. هدفت دراسة ريتش وآخرون (Rich ;et-al, 2009) هدفت هذه الدراسة الوصفية إلى تقيم ما تم تزويد

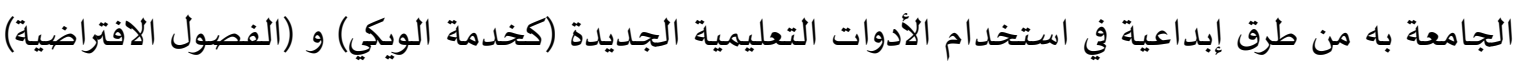

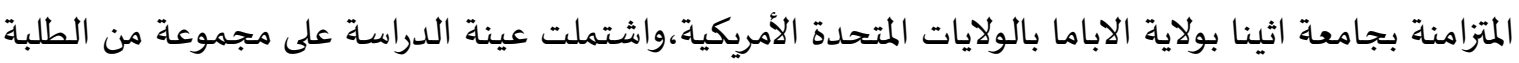


والمعلمين،وكانت أداة الدراسة هي الاستبيان، وتوصلت نتائج الدراسة إلى أن هناك عدد من الصعوبات التي

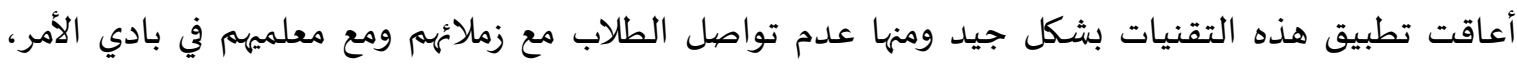
وتوصلت أيضاً إلى نجاح هذه التقنية في التعليم من خلال نجاح معلمي الكليات في تطبيقها وإيجاد الطرق

الفعالة لممارستها

وهدفت دراسة بودي (Bodie, 2009) هدفت هذه الدراسة التجريبية إلى استكشاف مدى تفاعل المعلم مع المعاسيا

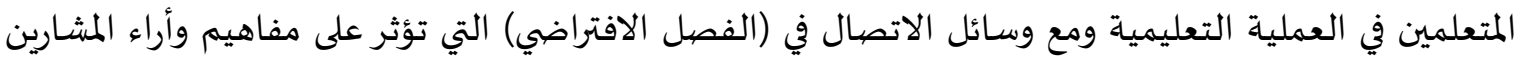

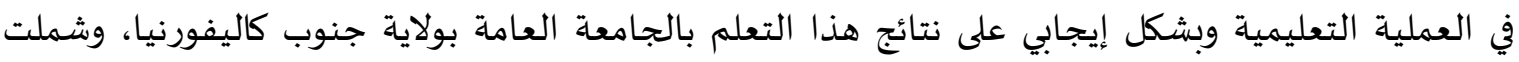

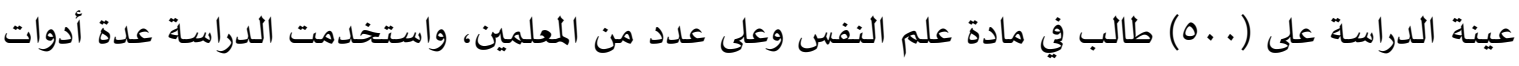

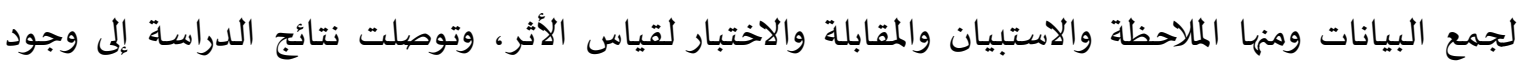

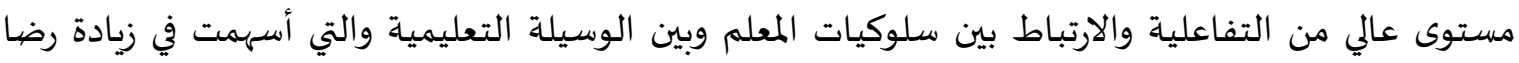
المتعلمين، وذلك من خلال أرائهم نحو هذه التقنية.

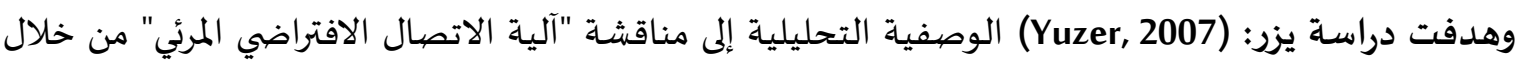

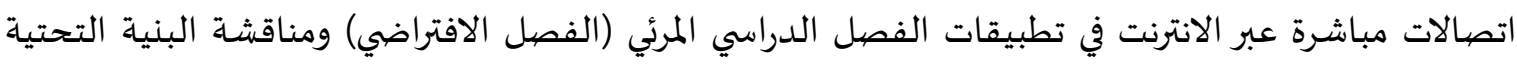

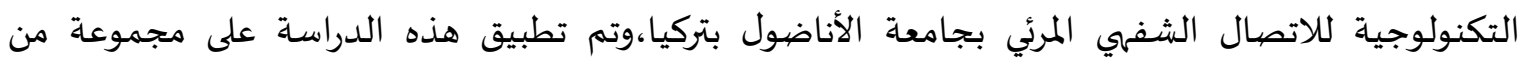

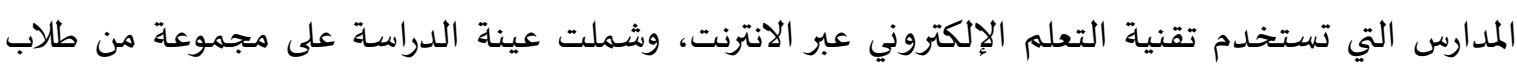

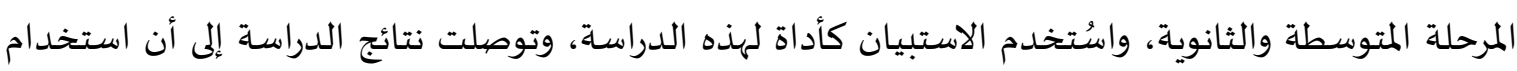

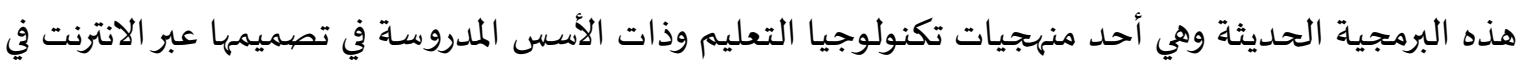
التدريس ثبتت أهميتها وفاعليتها في العملية التعليمية. هدفت دراسة باركر: (Parker, 2007) الوصفية إلى اكتشاف السمات والصفات والمهارات والتقنيات التي يتمتع

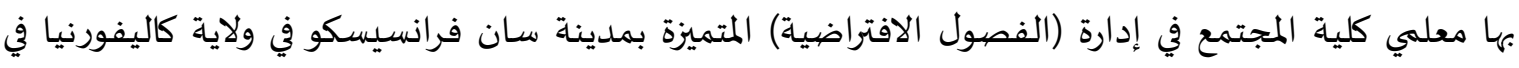

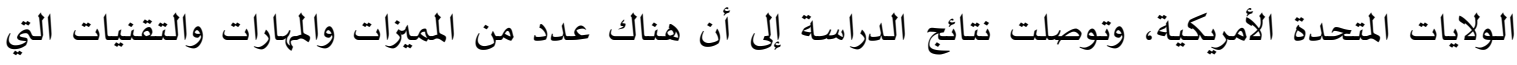

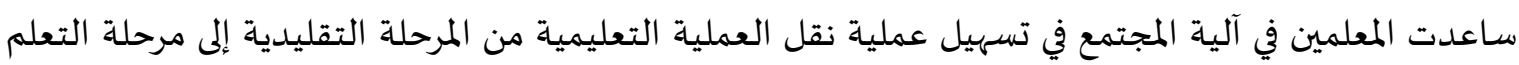
الإلكتروني. وهدفت دراسة ايدين ويزر: (Aydin \& Yuzer, 2006) هدفت هذه الدراسة الوصفية إلى تقييم (الفصل

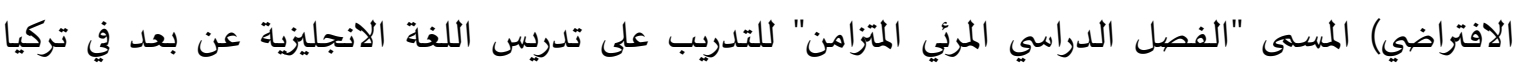

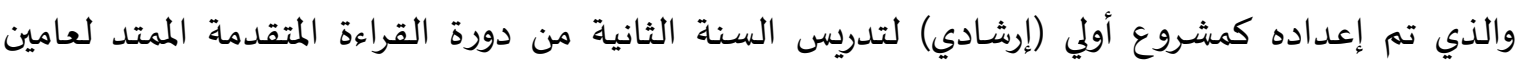

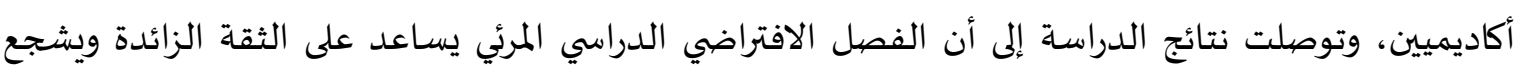

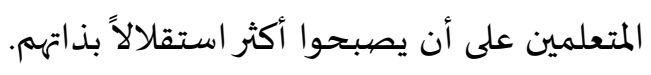

التعليق على الدراسات السابقة وعلاقتها بالدراسة الحالية:

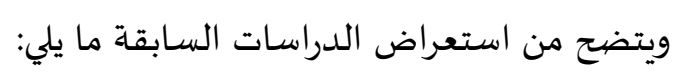

الأولى في الأردن وربما في العالم العربي - بحسب علم الباحث- التي تناولت واقع التعلم الإلكتروني في برنامج

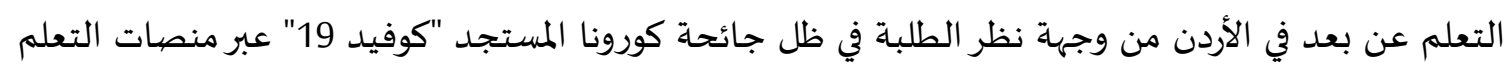

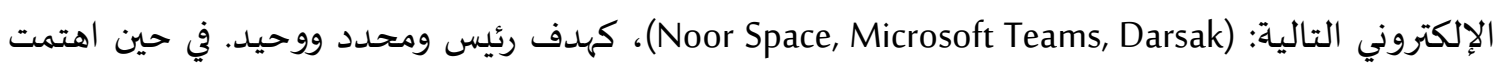


الدراسات السابقة بشكل عرضي، وضمن الاهتمام العام بالتعلم الإلكتروني، وبالنتيجة لم تلقِ الضوءَ الكافي

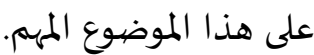
تتفق الدراسة الحالية مع بعض الدراسات السابقة في استخدامها المنهج الوصفي، ومنها دراسة كلٍ من ايدين

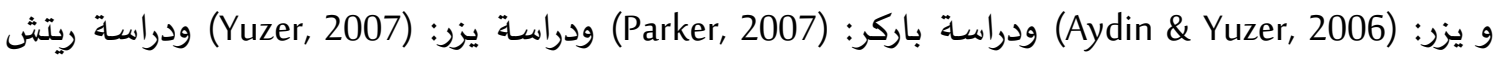

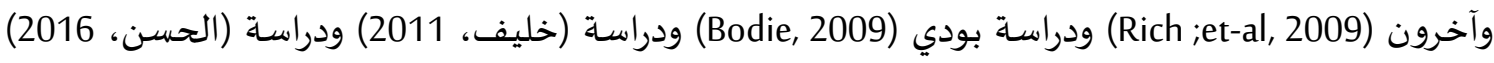

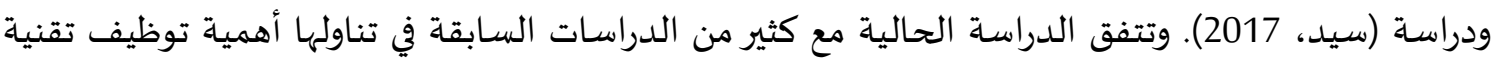

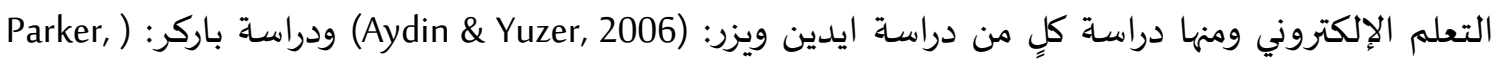

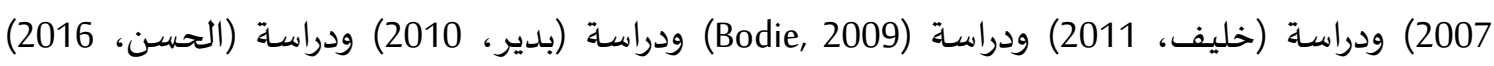

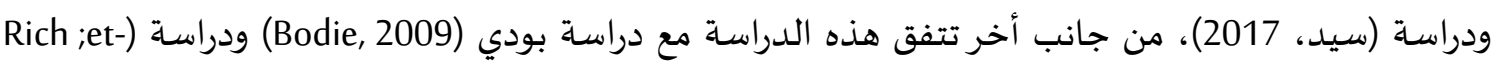

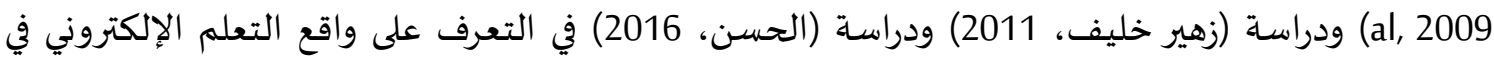

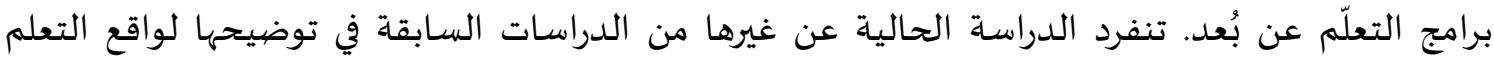

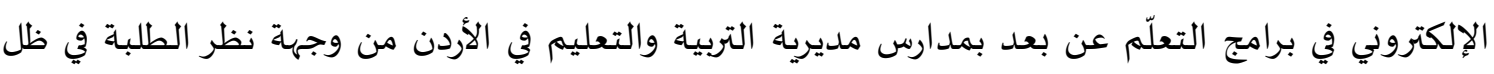

$$
\text { جائحة كورونا المستجد "كوفيد 19". }
$$

ومما لا شك فيه أنّ الدراسة الحالية قد أفادت من هذه المداد الدراسات السابقة ليس من حيث مراجعها، بل

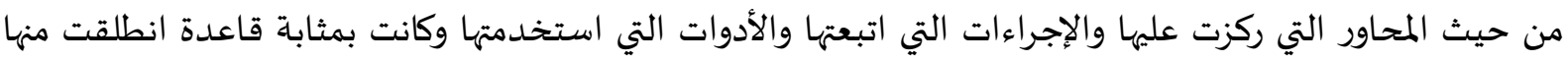

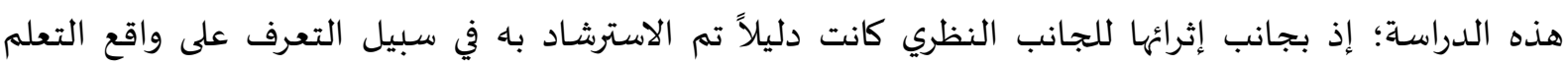

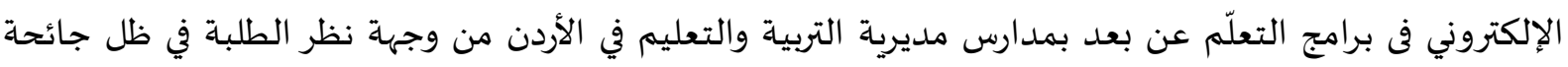
كورونا المستجدد "كوفيد 19".

3- منهرجية البحث واجراءاته

$$
\text { منهج البحث: }
$$

$$
\text { مجتمع البحث وعينته: }
$$

تألف مجتمع البحث جميع طلبة مدارس مديرية التربية والتعليم للواء المزار الشمالي، والبالغ عددهم مالئم (1200) طالباً وطالبة، في حين تألفت عينة البحث من (1200) طالباً وطالبة، من الفصل البحل الثاني للعام الدراسي الدياء

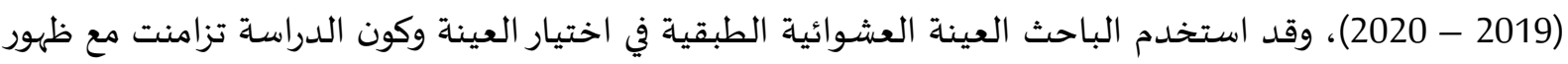

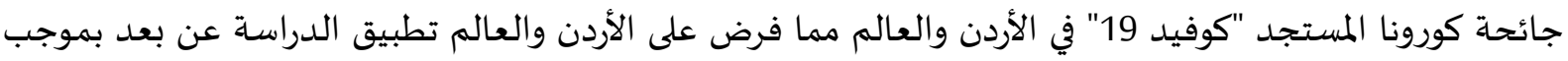

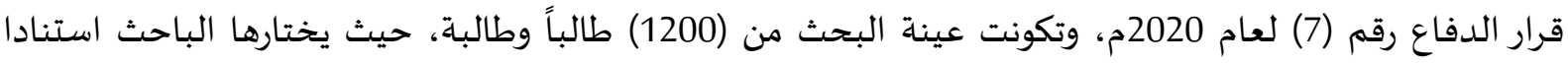

\begin{tabular}{|c|c|c|c|c|c|}
\hline النسبة \% & عينة الطالبات & عدد الطالبات & عينة الطلبة & عدد الطلبة & الصيف \\
\hline$\% 10$ & 13 & 130 & 12 & 120 & الأس \\
\hline
\end{tabular}

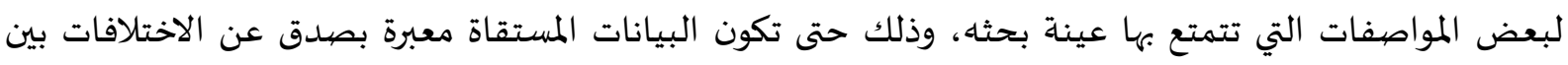
أفراد العينة (غربي، 2006، 137). والجدول (1) يبين نسب أفراد عينة البحث.

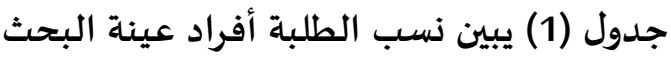


المجلة العربية للعلوم ونشر الأبحاث ـ مجلة العلوم التربوية والنفسية ـ المجلد الرابع ـ العدد الرابع والأربعون ـ نوفمبر 2020م

\begin{tabular}{|c|c|c|c|c|c|}
\hline النسبة \% & عينة الطالبات & عدد الطالبات & عينة الطلبة & عدد الطلبة & الصيف \\
\hline$\% 10$ & 13 & 130 & 12 & 120 & الثامن الأسـاسي \\
\hline$\% 10$ & 11 & 110 & 11 & 110 & التاسع الأسـاسي \\
\hline$\% 10$ & 12 & 120 & 12 & 120 & العاشر الأسـاسي \\
\hline$\% 10$ & 7 & 70 & 6 & 60 & الأول الثانوي \\
\hline$\% 10$ & 6 & 60 & 6 & 60 & الثاني الثانوي \\
\hline$\% 100$ & 62 & 620 & 59 & 580 & المجموع \\
\hline
\end{tabular}

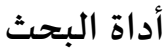

تمثلت أداة البحث في استبانة الكترونية تم توزيعها على عينة الدراسة الكترونيا وتم إعدادها وفق

الخطوات الآتية: - (الختات

- تحديد الهدف من الاستبانة: وهو التعرف إلى واقع التعلم الإلكتروني في برنامج التعلم عن بعد في ظل جائحة

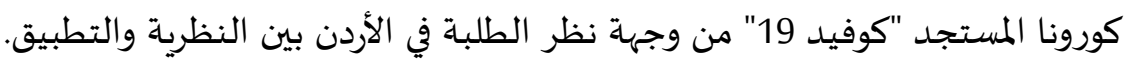
خطوات إعداد الاستبانة: ولقد تم إتباع الخطوات الآتية:

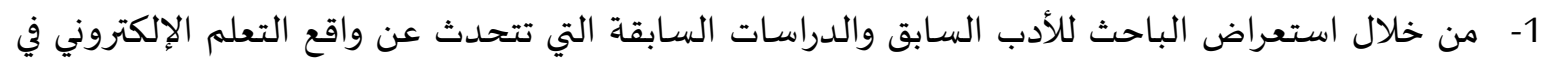
برنامج التعلم عن بعد في ظل جائحة كورونا المستجد "كوفيد 19" من وجهة نظر الطاتئ الطلبة في الأردن بين النظرية والتطبيق. 2- صياغة مفردات الاستبانة: استعان الباحث بمراجع عديدة في مجال القياس والتقويم، وذلك لتحديد

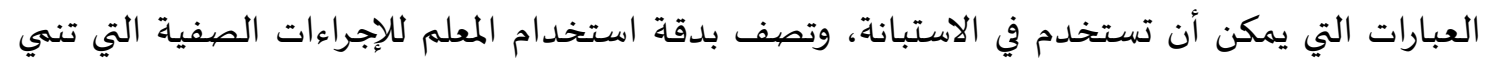
مهارات التفكير ومن هذه المراجع. 3- حرص الباحث عند صياغة العبارات أو الإجراءات أن تكون دقيقة، أن تصف بدار بدقة سلوك الطالب التي

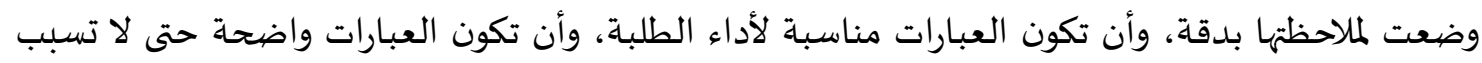

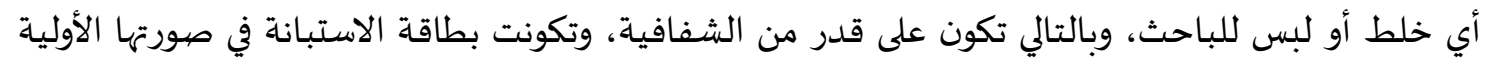
من (25) فقرة. وتم عرض الاستبانة على مجموعة من المحكمين والخبراء وبعد الأخذ برأي المحكمين وعددهيم (9)، وتعديلها وفق ما آراء المحكمين تم اعتماد تطبيقها على عينة الدراسية.

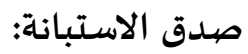

تحديد صدق الاستبانة: حيث تم عرضها على مجموعة من المحكمين بلغ عددهم (9) محكمين من ذوي

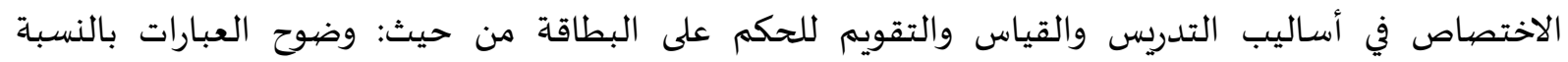
للإجراءات، ومدى مناسبة العبارات لموضوع البحث. وقد قام الباحث بإجراء التعديلات التي أبداها المحكمون.

حساب ثبات الأداة (الاستبانة) تم حساب ثبات الأداة بطريقة الاتساق الداخلي باستخدام معادلة (كرو نباخ ألفا) حيث بلغت نسبة ثباتها (0,85) زمن تطبيق الاستبانة. 
4- عرض النتائج وتفسيرها:

•إجابة السؤال الأول: "ما أهمية استخدام التعلم الإلكتروني في برنامج التعليم عن بعد"؟

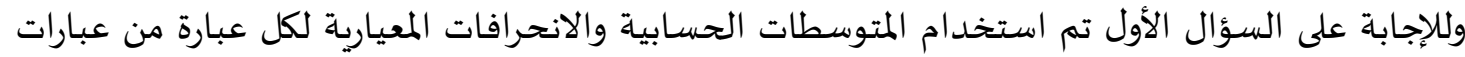
المحور الأول والمتعلق بالتعرف على أهمية التعلم الإلكتروني في برنامج التعليم عن بعد من وجهابة نظر الطلبة،

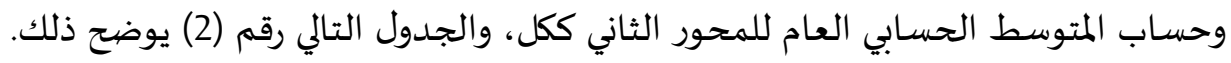

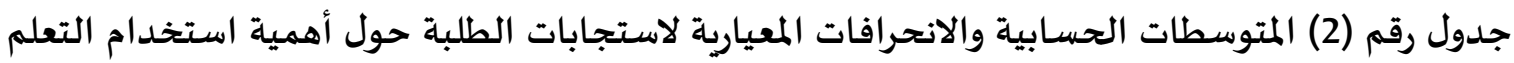

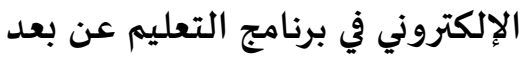

\begin{tabular}{|c|c|c|c|c|c|c|c|c|c|c|}
\hline الترتيب & المقياس & الاندراف & المتوسط الحسابي & بشارض & معارض & محايل & موافق & 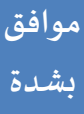 & العبارة & $\hat{\imath}$ \\
\hline 1 & موافق & 0.78 & 4.40 & 2.5 & 0.0 & 3.3 & 43.3 & 50.8 & تساعد في توظيف التقنيات & 5 \\
\hline 2 & 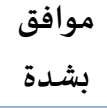 & 0.77 & 4.28 & 2.5 & 0.0 & 5.0 & 51.7 & 40.8 & تسـاعد على تحديث وتطوير & 15 \\
\hline 3 & 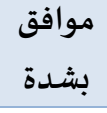 & 0.82 & 4.26 & 2.5 & 0.8 & 6.7 & 47.5 & 42.5 & نظام تقني ومتقدم ومهم & 20 \\
\hline 4 & موافق & 0.82 & 4.25 & 2.5 & 0.0 & 9.2 & 46.7 & 41.7 & 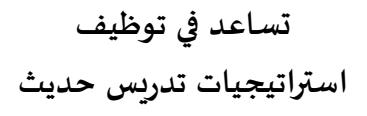 & 4 \\
\hline 5 & موافق & 0.79 & 4.24 & 2.5 & 0.8 & 5.0 & 53.3 & 38.3 & تسـاعد على تحقيق أهداف & 2 \\
\hline 6 & موافق & 0.88 & 4.19 & 2.5 & 0.8 & 13.3 & 41.7 & 41.7 & تنمي مهارات التعلم الذاتي & 9 \\
\hline 7 & موافق & 0.90 & 4.13 & 3.3 & 1.7 & 10.0 & 48.3 & 36.7 & توفر هذه التقنية للطالب & 18 \\
\hline 8 & موافق & 0.83 & 4.10 & 2.5 & 3.3 & 5.0 & 59.2 & 30.0 & تساعد في اكتساب مهارات & 14 \\
\hline 9 & موافق & 0.92 & 4.10 & 3.3 & 2.5 & 10.8 & 47.5 & 35.8 & للفصيول الافتراضية ايجابيات & 8 \\
\hline 10 & موافق & 0.94 & 4.03 & 2.5 & 5.0 & 12.5 & 46.7 & 33.3 & 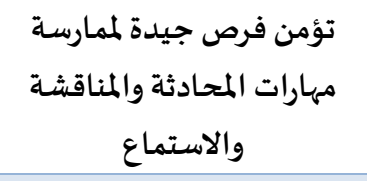 & 7 \\
\hline 11 & موافق & 0.84 & 4.02 & 2.5 & 1.7 & 14.2 & 53.3 & 27.5 & التعلم إلكتروني نظام تعليمي & 3 \\
\hline 12 & موافق & 0.88 & 4.00 & 3.3 & 0.8 & 15.8 & 51.7 & 28.3 & تلطالب مساحة التعلم الإلكتروني من الحرية & 17 \\
\hline 13 & موافق & 0.92 & 3.95 & 2.5 & 4.2 & 17.5 & 46.7 & 29.2 & تسـاعد في تبادل خبرات & 11 \\
\hline
\end{tabular}




\begin{tabular}{|c|c|c|c|c|c|c|c|c|c|c|}
\hline الترتيب & المقياس & الاندراف & المتوسط الحسابي & بشارض & معارض & محايد & موافق & بشوافق & العبارة & $\hat{\imath}$ \\
\hline 14 & موافق & 1.02 & 3.95 & 4.2 & 3.3 & 19.2 & 39.2 & 34.2 & تلسـاعد على التدريب المستمر & 19 \\
\hline 15 & 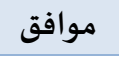 & 0.85 & 3.90 & 2.5 & 1.7 & 21.7 & 51.7 & 22.5 & تلبي حاجات الطالب. & 6 \\
\hline 16 & موافق & 0.90 & 3.87 & 2.5 & 3.3 & 22.5 & 47.5 & 24.2 & $\begin{array}{c}\text { تسـاعد على تنمية مهارات } \\
\text { التفكير العلمي }\end{array}$ & 16 \\
\hline 17 & موافق & 0.91 & 3.82 & 4.2 & 2.5 & 19.2 & 55.0 & 19.2 & تسـاعد التعلم الإلكتروني في & 1 \\
\hline 18 & موافق & 1.03 & 3.75 & 3.3 & 8.3 & 23.3 & 39.2 & 25.8 & المشترك بين المعلم والطالب. & 10 \\
\hline 19 & موافق & 1.06 & 3.71 & 3.3 & 9.2 & 26.7 & 34.2 & 26.7 & حمدي الى زيادة دافعية & 12 \\
\hline 20 & معارض & 1.01 & 1.99 & 35.5 & 36.7 & 18.3 & 4.2 & 3.3 & نظام غير مجد في عملية & 13 \\
\hline & موافق & 0.65 & 3.94 & & & & & & \multicolumn{2}{|l|}{ المتوسط الحسابي العام = } \\
\hline
\end{tabular}

تشير نتائج الجدول رقم (2) أن المتوسطات الحسابية والانحرافات المعيارية الخاصة بوجهات نظر أفراد

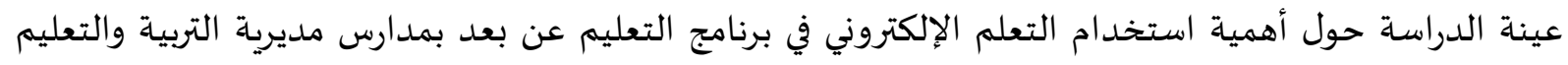

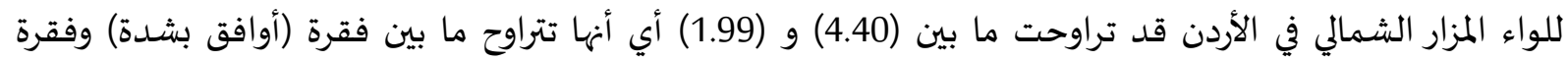

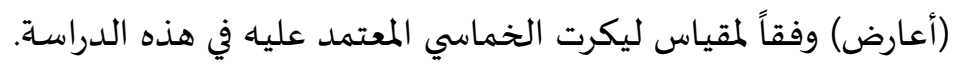

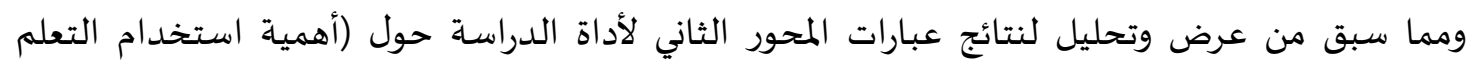

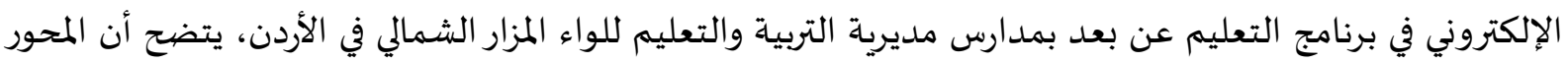

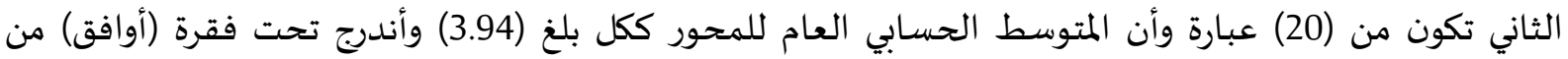

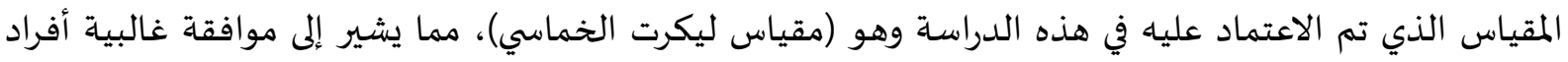

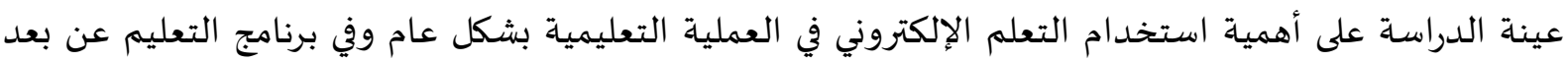
بشكل خاص وهذا ما توصلت إليه بحوث ودراسات كثيرة قارنت بين التعليم التقليدي والتعليم عن طريق التعلم الإلكتروني والتي أثبتت نتائجها تفوق المجموعات التي تعلمت عن طريق التعلم الإلكتروني على المجموعات التيه تعلمت عن طريق الفصول التقليدية، وهذا ما يفسر ارتفاع درجة موافقة عينة الدراسة لعبارات المحور العام.

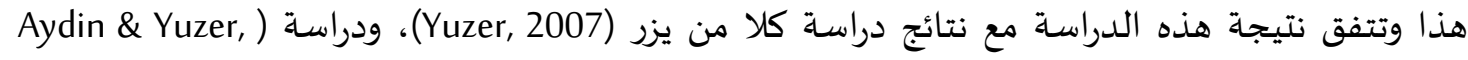

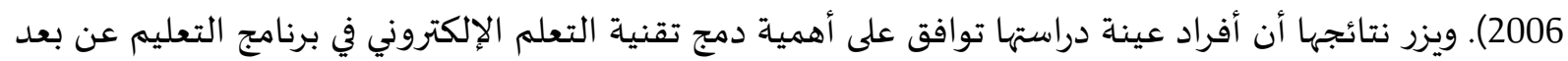
لما لها من فوائد كثيرة تساعد على حل الكثير من مشكلات اتفراد العملية التعليمياة.

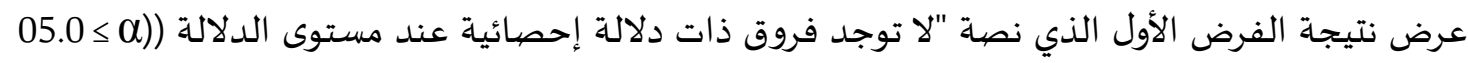

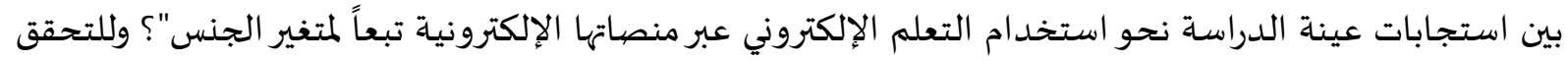
من هذا الفرض تم استخدام تحليل التباين الأحادي (Anova) لاستجابات أفراد العينة حول واقع التعلم الإلكتروني

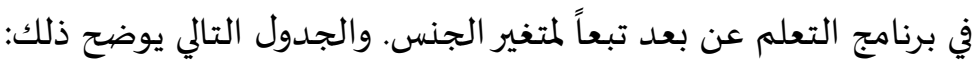


الجدول رقم (6) نتيجة اختبار تحليل التباين الأحادي للمقارنة بين آراء أفراد العينة حسب متغير الجنس

\begin{tabular}{|c|c|c|c|c|c|c|}
\hline التعليق & مستوى الدلالة & $F$ & متوسط مجموع & الحرجة & المربعات & مصهدر التباين \\
\hline \multirow{3}{*}{ غير دالة } & \multirow{3}{*}{0.374} & \multirow{3}{*}{1.948} & 0.385 & 3 & 1.154 & بين المجموعات \\
\hline & & & 0.367 & 116 & 42.536 & داخل المجموعات \\
\hline & & & & 119 & 43.681 & المجموع \\
\hline
\end{tabular}

بالرجوع إلى الجدول رقم (6) يلاحظ أن قيمة (f) تبعاً لمتغيرات الجنس بين المجموعات وداخل المجموعات

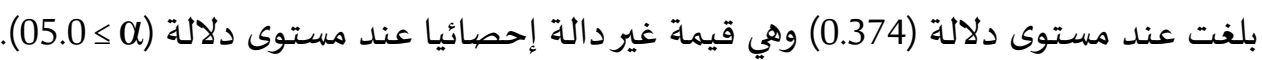

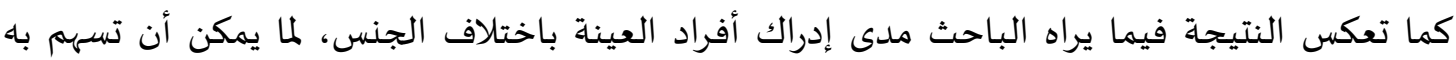

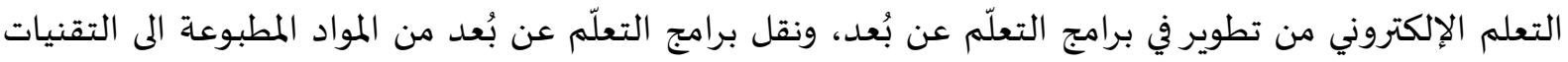

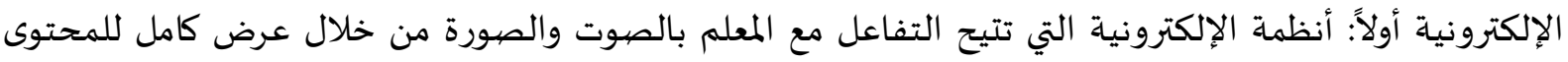
العلمي على الهواء مباشرة مما يساعد على تحقيق الأهداف التعليمية بسرعة عالية وفعالية وبشكل واقعى مما يُكون لله الأثر الإيجابي على المتعلمين.

$$
\text { التوصيات - والمقترحات: }
$$

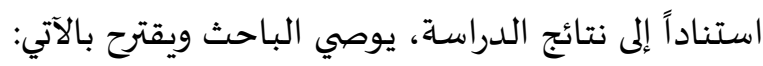

توعية المعلمين في مدارس مديرية التربية والتعليم للواء المزار الشمالي للاستفادة من تقنية التعلم الإلكتروني

$$
\text { وذلك لتسهيل وتحسين الممارسة التعليمية التعلمية لاسيما في التعلم عن بعد. }
$$

تقوية الاتجاه الإيجابي نحو توظيف تقنية التعلم الإلكتروني بمدارس مديرية التربية والتعليم للواء المزار

$$
\text { الشمالي. }
$$

الاستفادة من تجارب والخبرات العربية والعالمية في مجال توظيف تقنية التعلم الإلكتروني في برامج التعلّم عن

بعُد.

دراسة اتجاهات الطلبة نحو استخدام برامج التعلم الإلكتروني.

وضع تصور مقترح لإنشاء فصل افتراضي تزامني في برامج التعلّم عن بعد. تصدئ.

قائمة المراجع

أولاً - المراجع بالعربية:

- أبو عليا، عبد الله. (2013): دليل استخدام المدرس لنظام التعلم الإلكتروني، مركز التعلم الإلكتروني، رياض ومدارس جامعة الزرقاء، الأردن.

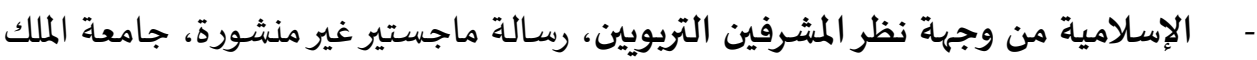

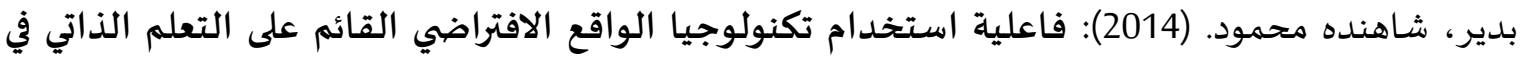

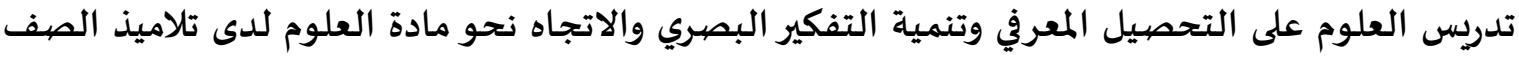

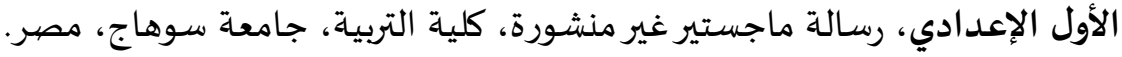




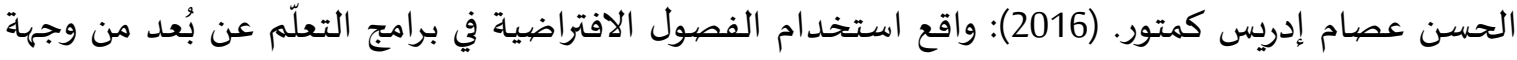

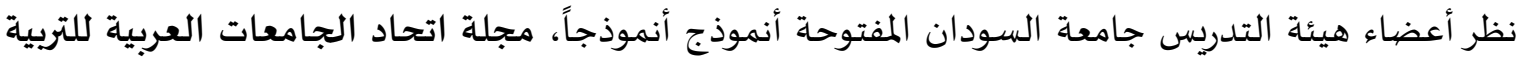
وعلم النفس، دمشق.

الحسيني، فايزة أحمد مجاهد. (2012): استخدام الفصيول الافتراضية في تدريس التاريخ وأثرها على التحصيل وتنمية مهارات التفكير الناقد وبعض مهارات التواصل الإلكتروني لدى الطالبات المعلمات بكلية التربية، مجلة الجمعية التربوية للدراسات الاجتماعية، العدد (45)، كلية التربية، جامعة عين شمس.

خليف، زهير ناجي. (2011): استخدام الفصول الافتراضية من وجهة نظر الطلبة وطلاب الثانوية العامة في فلسطين، المؤتمر الدولي الثاني للتعلم الالكتروني والتعلم عن بعد، المركز الوطني للتعلم الالكتروني والتدريب عن بعد، السعودياة، الرياض. خليف، زهير ناجي. (2009): تقييم تجربة استخدام الفصول الافتراضية لتقويم الدروس لطلبة الثانوية العامة، ورقة عمل مقدمة للمشاركة في العملية التعليمية في القرن الواحد والعشرين، واقع وتحديات، جامعاة النجاح الوطنية، نابلس، فلسطين. رزق، فاطمة مصطفى. (2008): أثر الفصول الافتراضية على معتقدات الكفاءة الذاتية والأداء التدريسي لمعلمي نائي العلوم قبل الخدمة". مجلة القراءة والمعرفة. العدد 90. 212 - 257. سيد، محمود أبو الحجاج خضاري. (2017): استخدام الفصول الافتراضية لتنمية التحصيل المعرفي ومهارات

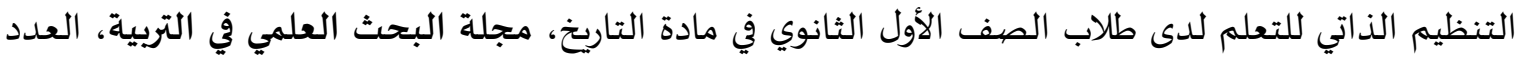
$388-371$ ، (18)

غربي، علي. (2006): أبجديات المنهجية في كتابة الرسائل الجامعية. الجزائر.

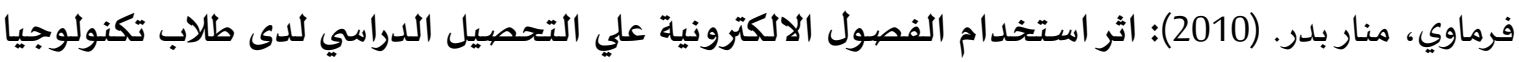

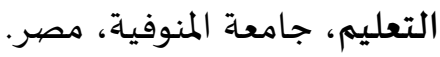

ثانياً - المراجع بالإنجليزية:

- Aydin B. \& Yuzer, T. V. (2006). Building a Synchronous Virtual Classroom in a Distance English Language Teacher Training (DELTT)" Program in Turkey, [Electronic version]. Journal of Bibliographic Research, 7, 1.

- Bodie L. W. (2009). An Experimental Study Of Instructor Immediacy In the Wimba Virtual Classroom, Unpublished doctoral dissertation, San Diego, USA.

Florence Martin \& Michele A. Parker, (2014): Use of Synchronous Virtual Classroom: Why, Who, and How? Department of Instructional Technology Foundation and Secondary Education University of North Carolina at Wilmington Merlot, Journal of Online Learning and Teaching, Vol, (10), No, (2).

- Lim, Jon \& Karol, Jonathan: (2004) Student Achievement, Satisfaction and Instructional Delivery Models, TRE-Systems, Miami, USA.

- Lisa Logan Riche \& Wendy Cowan, (2009): Collaborate, Engage, and Interact in online Learning Successes with Wikis and Synchronous Virtual classrooms at Athens State University 300 North Beatty Street Athens, Alabama. 
- Murry, T. L. (2005). Exploring the Psychological Terrain of the Virtual Classroom: The nature of Relationship and Power in online Teaching and Learning, Unpublished doctoral dissertation, Albany State, USA.

- Parker, C. A., June (2007). Exploring the qualities, skills, attitudes and techniques among highly Rated community college teachers that may foster community, connectedness and discourse in the virtual classroom: A Qualitative study, Unpublished doctoral dissertation, San Francisco, USA.

- $\quad$ Rich, L. L., Cowan, W., Herring, S. D. \& Wilkes, W. (2009) Collaborate, Engage, and Interact in Online Learning: Successes with Wikis and Synchronous Virtual Classrooms at Athens State University [Electronic version]. Journal of Bibliographic Research, 7, 14.

- Wang, A, Y, and Newlin, M H. (2002) Predictors of Web-Student Performance, the role of self-efficacy and Reasons for Taking an on-line Class, Computers in Human Behavior, 18 (2) 151-163.

- Yuzer T. V. (2007). Generating Virtual Eye Contacts Through Online Synchronous Communications in Virtual Classroom Application, [Electronic version]. Journal of Bibliographic Research, 8, 3. 